\title{
LA APROPIACIÓN DE LA LENGUA ESCRITA: UN PROCESO CONSTRUCTIVO, INTERACTIVO Y DE PRODUCCIÓN CULTURAL
}

\author{
M.Sc. Ana Lupita Chaves Salas
}

\section{Introducción}

Desde muy corta edad los niños y las niñas manifiestan en sus juegos iniciativas por aprehender los códigos escritos. En sociedades alfabetizadas como la nuestra, muchos pequeños y pequeñas aprenden a leer y a escribir de manera natural, sin escolaridad formal (Molina, 1998). Las investigaciones sobre los procesos iniciales de la lectoescrita muestran al párvulo como un aprendiz activo que trata de comprender el lenguaje escrito que está a su alrededor, explora, pregunta, formula y comprueba hipótesis en su intento de comunicarse con el mundo. Al respecto Ferreiro indica:

" ...sabemos, gracias a la obra monumental de Piaget, que los niños no esperan tener seis años y una maestra delante para comenzar a reflexionar acerca de problemas extremadamente complejos, y nada impide que un niño que crece en una cultura donde la escritura existe reflexione también acerca de esta clase particular de marcas y organice sus ideas al tratar de comprenderlas" (1983, p. 79)

El niño y la niña se van apropiando de la lengua escrita de una forma natural mediante experiencias de lenguaje que se presentan en las situaciones sociales cotidianas y de juego que tienen sentido para él y para ella (Ruiz,1994).

En este contexto son cuestionables las prácticas que se desarrollan en los centros de educación inicial con el fin de "preparar" a las y los educandos para que enfrenten con éxito las distintas tareas que demanda el aprendizaje de la lectura, la escritura y el cálculo, y que, en muchos casos, representan actividades repetitivas y sin sentido, donde se supone que la y el sujeto aprenden por simple repetición como un ser pasivo y mecánico.

Este artículo hace referencia a investigaciones y a teorías que conciben la apropiación de la lengua escrita de parte del sujeto como un proceso constructivo, interactico y de producción cultural. Desde esta perspectiva el propósito del artículo es invitar a reflexionar sobre la pertinencia de las prácticas pedagógicas que desarrollamos en nuestros centros educativos en este campo. 


\section{Nuevas perspectivas pedagógicas en el aprendizaje de la lengua escrita}

En las últimas décadas las investigaciones en torno a la forma cómo los niños y las niñas aprenden y se apropian ${ }^{2}$ de la lengua escrita ha cambiado radicalmente, son numerosos los aportes intelectuales que han contribuido con este fenómeno, entre ellos, la teoría sociocultural de Lev Vigotsky (1885-1934), la teoría cognitiva de Jean Piaget (1896-1981) y la teoría sociopolítica de Paulo Freire (1921-1997).

Con base en esas teorías se han realizado diversas investigaciones y se han formulado nuevas propuestas pedagógicas sobre el aprendizaje de la lectoescritura, entre ellas: la psicogenésis de la lengua escrita de Emilia Ferreiro (1983), las funciones lingüísticas de Halliday (1986) y la teoría psicolingüística de Kenneth y Yetta Goodman(1989)

Ferriero(1983-1994) en sus investigaciones sobre el proceso de apropiación de la lengua escrita encuentra que los niños y las niñas pasan por una serie de niveles y subniveles en el proceso de aprendizaje ${ }^{3}$; y al ingresar a la escuela poseen algunas concepciones sobre la escritura, es decir, que desde edades muy tempranas los párvulos se han apropiado de la información escrita transmitida de diversas fuentes: empaques de galletas, refrescos, periódicos, libros, entre otros materiales. Es así como en el proceso de aprendizaje de la lectoescritura interviene en gran medida el contexto sociocultural y la función social que tiene la lengua escrita para comunicar significados ya que por medio de esta se trasmite lo que la persona piensa, cree, conoce y siente.

M.A.K. Halliday (1986) menciona siete categorías de funciones lingüísticas que se desarrollan en el contexto social y que se aplican tanto a la lengua oral como a la lengua escrita, éstas son las siguientes: instrumental, es el lenguaje que se utiliza para satisfacer necesidades; regulatoria, es el que se usa para controlar la conducta de otros; interaccional, se refiere al lenguaje para mantener y establecer relaciones sociales; personal, es aquel que permite expresar opiniones personales; imaginativa, permite expresar lo que imaginamos y creamos; el lenguaje heurístico, permite crear información y respuestas acerca de diferentes cosas que se desean conocer; lenguaje informativo, es el que permite comunicar información.

Es decir, en la apropiación de la lengua escrita es fundamental el contexto sociocultural y el uso funcional que le dé el niño y la niña al lenguaje para comunicar significados, por tal razón es necesario que las y los educadores y otros adultos que interactuan con los niños y las niñas promuevan en ellos y ellas la capacidad comunicativa en

\footnotetext{
${ }^{2}$ La apropiación es sinónimo de adaptación que se da mediante procesos culturales y naturales. Consultar este término en Barquero,1996, pag.156.
} 
todas sus formas, lo que le permitirá la socialización de sus actos, la integración con la cultura y conocer el mundo.

Numerosas investigaciones (Norman Jackson, 1982, Chomsky,1971; Clay,1975; Cohn,1981 citadas por Ruiz,1996) sobre los lectores naturales, es decir niños y niñas que aprenden a leer en su hogar y sin instrucción formal, coinciden en que el lenguaje emerge de una necesidad de comunicarse con los demás y que el ambiente sociocultural ejerce una gran influencia en el desarrollo de esta habilidad. Estos ambientes se caracterizan por la interacción verbal que se da entre los miembros de la familia, donde el niño y la niña tienen acceso a todo tipo de materiales para la lectura y la escritura, donde la lectura es una actividad cotidiana y los adultos manifiestan interés por el valor del lenguaje escrito y responden a la curiosidad de los párvulos sobre éste y a su esfuerzo por interpretarlo, de tal manera "...la habilidad para leer no emerge de un vacío sino que se fundamenta en el conocimiento preexistente del niño y la niña sobre el lenguaje, y se construye mediante un proceso dinámico en el cual interactúan y se apoyan los cuatro procesos del lenguaje: escuchar, hablar, escribir y leer" (Ruiz, 1996, p. 43).

Todos éstos aportes teóricos indican que el conocimiento sobre el lenguaje escrito se construye mediante la participación activa de la persona en el contexto natural y cotidiano al utilizarlo de una manera funcional con sentido y significados reales.

Otro aporte importante, es la teoría sociolingüística de Kenneth y Yetta Goodman (1989), ellos construyen una propuesta pedagógica para el aprendizaje de la lectura y la escritura que emerge de las teorías y los estudios citados anteriormente, y de las investigaciones que ellos mismos realizaron con estudiantes de diferentes niveles educativos y pertenecientes a diversos grupos étnicos en los Estados Unidos: comunidades de inmigrantes árabes, texanos hablantes de español, indios americanos de la tribu Navajo, hawaianos-samoanos y negros de la zona rural de Mississipi, los cuáles tuvieron éxito en el aprendizaje de una segunda lengua (Goodman,1989).

Esta propuesta pedagógica considera fundamental partir de las realidades socioculturales de las y los educandos, de su lenguaje, de lo que es significativo de acuerdo con su realidad. Promueve el diálogo entre educadores, educadoras y educandos para incorporar experiencias de vida, costumbres, visiones de mundo; y recomienda la construcción de textos y prácticas educativas con base en los intereses y necesidades de las y los estudiantes. En este contexto se respeta al estudiante, su origen, su forma de

\footnotetext{
${ }^{3}$ Para mayor información sobre la psicogénesis de la lengua escrita consultar, Ferreiro,1997
} 
hablar y se le estima en toda su diversidad, lo que implica que se da valor a lo que piensa y siente.

Esta propuesta critica los métodos tradicionales de la enseñanza de la lectoescritura que limitan los procesos de lectura, escritura y pensamiento a técnicas mecánicas enajenantes sin sentido, ignorando la cultura y las formas de lenguaje de las y los educandos, lo que contribuye a formar identidades pasivas pues el poder y el conocimiento esta en la o el educador.

Para Giroux (1995) esos métodos tradicionales de alfabetización responden a los intereses de la cultura dominante que no se preocupa por formar personas críticas que impulsen las transformaciones que la sociedad necesita.

\section{Reflexiones finales}

Las nuevas contribuciones teóricas y prácticas en torno a los procesos iniciales del aprendizaje de la lectura y la escritura, nos llevan a cuestionar las prácticas pedagógicas que desarrollamos en los centros de educación inicial con el propósito de "preparar" al niño y a la niña para el ingreso a la escuela. Es necesario un cambio educativo que lleve a la transformación de este nivel, para ello es preciso que educadoras y educadores reflexionemos y nos planteemos interrogantes sobre nuestra acción pedagógica, para estar conscientes de lo que hacemos ¿Por qué? y ¿Para qué?. Es importante que nos preguntemos: ¿Cómo incentivamos los procesos iniciales de lectoescritura en nuestros estudiantes? ¿Usamos las hojas de apresto y por qué? ¿Cuál ha sido nuestra experiencia en este campo? ¿En el planeamiento didáctico tomamos en cuenta las experiencias previas de los niños y las niñas? ¿Qué nivel de participación tiene la familia? ¿Damos oportunidad para que las y los educandos conversen sobre sus vivencias, creencias, conocimientos, pensamientos y sentimientos? ¿Partimos del análisis de las diferentes realidades socioculturales de donde proceden nuestros estudiantes? ¿Cómo creemos que aprende el ser humano? ¿Conocemos las hipótesis que han construido nuestros estudiantes sobre el lenguaje escrito? ¿Cuántas oportunidades brindamos a los niños y a las niñas para que hablen, escriban, lean y escuchen? ¿El ambiente físico y afectivo del aula incentiva en los niños a dibujar, escribir, leer, escuchar y conversar? ¿Promovemos el diálogo con nuestros educandos? ¿Cómo propiciamos la participación de los niños y las niñas? ¿Propiciamos el juego cooperativo con actividades que incentiven el desarrollo del lenguaje en los pequeños: dramatizaciones, conferencias, elaboración de carteles, cuentos, cartas, mensajes, poesías, 
canciones, lectura de cuentos y poesías, entre otras? ¿Qué tipo de ser humano queremos ayudar a construir y para qué sociedad?

La respuesta a éstas preguntas nos permitirán profundizar en el significado de nuestra práctica pedagógica, analizar nuestras creencias, tomar conciencia a favor de quién trabajamos y en contra de quién, lo que contribuirá a promover las transformaciones que requiere el nivel de educación inicial.

\section{Referencias}

Barquero, R. (1996). Vigotsky y el aprendizaje escolar. Buenos Aires, Argentina: Aique.

Coll, Cesar; Solé, Isabel. (1998). Los profesores y la concepción constructivista. En EI constructivismo en el aula (pp. 7-23). $8^{a}$ edición. Barcelona, España: GRAÓ.

Ferreiro, Emilia; Teberosky, Ana. (1982). Prólogo e introducción. En La teoría de Piaget: Investigaciones en los sistemas de escritura (pp. 10-47). Barcelona, España: Siglo XXI.

Ferreiro, Emilia. (1983). Psico-génesis de la escritura. En Cesar Coll (Comp.) Psicología genética y aprendizajes escolares. Barcelona, España: Siglo XXI.

Ferreiro, Emilia. (1997). Alfabetización. Teoría y práctica. México: Siglo Veintiuno.

Goodman, K. (1993). El Lenguaje Integral como Filosofía Educativa. En Memoria del Primer Congreso de las Américas sobre Lectoescritura 1992 (pp. 4-29). Maracaibo, Venezuela: Universidad de los Andes.

Goodman, Kenneth; Goodman, Yeta. (1993). Vygotsky desde la perspectiva del lenguaje total. En Vygotsky y la educación (pp. 263-292). $2^{a}$ Edición. Buenos Aires, Argentina: Aique.

Halliday, M. A. K. (1986). El lenguaje como semiótica social. México: Fondo de cultural económica.

Matos, J. (1995). El paradigma sociocultural de L. S. Vigostky y su aplicación en la educación. (mimeo). Heredia, Costa Rica: Universidad Nacional. 13 p.

Molina, Ángeles (1998). Reseña del libro La alfabetización temprana en el ambiente preescolar: Nuevas perspectivas para leer y escribir, de Daisy Ruiz. Pedagogía, 32. San Juan Puerto Rico: Recinto de Río Piedras, Facultad de Educación. Universidad de Puerto Rico 108 -112.

Moll L. (1993). Vygotsky y la educación. 2ª edición. Buenos Aires: Aique.

Morales, P. (1990). El papel del lenguaje en el desarrollo cognoscitivo: anteposición de la perspectiva piagetiana frente a la perspectiva soviética (mimeo). Puerto Rico: Recinto de Río Piedras. Universidad de Puerto Rico. 
Papalia, Diane; Wendkos, Sally. (1997). Psicología del Desarrollo. $7^{\text {a }}$ Edición. Santa Fé de Bogotá, Colombia: McGraw Hill.

Ruiz, Daisy. (1996). La alfabetización temprana en el ambiente preescolar. San Juan, Puerto Rico: Facultad de Educación, Universidad de Puerto Rico. Recinto Río Piedras. 